ORIGINAL ARTICLE

\title{
Detection of severe protein-energy malnutrition by nurses in The Gambia
}

\author{
C Hamer, K Kvatum, D Jeffries, S Allen
}

Arch Dis Child 2004;89:181-184. doi: 10.1136/adc.2002.022715

See end of article for authors' affiliations .....................

Correspondence to: $\mathrm{Dr} C \mathrm{Hamer}$, Lecturer in Community Child Health at Bristol University, Centre for Child and Adolescent Child Health, Hampton House, Cotham Hill, Bristol BS6 6JS, UK:

Clare.Hamer@

bristol.ac.uk

Accepted 26 May 2003

\begin{abstract}
Aim: To test whether nurses can use the WHO integrated management of childhood illness (IMCI) nutrition algorithm to identify reliably severe protein-energy malnutrition in children.

Methods: Nurses were trained to identify severe protein-energy malnutrition using $\mathrm{IMCl}$ training materials. They identified visible severe wasting and bipedal oedema, and categorised weight-for-age using a growth chart, in consecutive children attending outpatient clinics. Their findings were compared with weight for height Z (WHZ) score, bipedal oedema assessed by a trained observer, and weight-for-age Z score.

Results: A total of 352 children were recruited, of whom $34(9.7 \%)$ were severely wasted (WHZ score $<-3)$ and $18(5.1 \%)$ had bipedal oedema. In the detection of severe wasting, the nurses' assessments showed $56 \%$ sensitivity, $95 \%$ specificity, and $56 \%$ positive predictive value (PPV), and for bipedal oedema $22 \%, 99 \%$, and $57 \%$ respectively. Overall, the nurses identified only half of 50 children with severe wasting and/or bipedal oedema and wrongly identified a further 13 children as severely malnourished. Plotting weight for age by the nurses showed 62\% sensitivity, $99 \%$ specificity, and $89 \%$ PPV for the detection of children with very low weight.

Conclusions: Severe malnutrition was both under-diagnosed and wrongly diagnosed by nurses trained in the use of the IMCI nutrition algorithm in a clinic setting in The Gambia. These guidelines for health workers and the training materials, particularly with respect to calculation of age, need further development to improve the detection of malnourished children.
\end{abstract}

n 2000, 149.6 million children $(26.7 \%$ of the world's population of children) were at least moderately malnour-

ished. ${ }^{1}$ Over half of all child deaths in developing countries have been attributed to the potentiating effect of malnutrition, ${ }^{2}$ and nutritional status is closely related to case fatality in children admitted to health facilities. In 13579 children aged 5 years or less admitted to two hospitals in The Gambia, the most underweight (weight for age $\mathrm{Z}$ (WAZ) score $<-4$ ) had a case fatality of $22.7 \%$ compared with $7.2 \%$ for better nourished children (WAZ score $>-2$ ). ${ }^{3}$

The recognition of severe malnutrition in hospital is important because standard management protocols can greatly reduce mortality. ${ }^{4}$

In the recent WHO guidelines for the management of severe malnutrition, severely malnourished children are identified by calculation of weight for height and the detection of bipedal oedema. ${ }^{5}$ Severe wasting is defined as a weight for height $\mathrm{Z}$ (standard deviation) score of less than 3 below the mean for the reference population (WHZ $<-3$ ).

The WHO has developed integrated management of childhood illness (IMCI) guidelines to help health workers in first level facilities in developing countries to identify and manage sick children. These rely on the detection of several key symptoms and clinical signs. ${ }^{6}$ Length or height is not usually measured in primary level clinics because it is time consuming and difficult to do accurately. Therefore, the IMCI guidelines recommend that health workers identify severe protein-energy malnutrition by the presence of visible severe wasting and bipedal oedema. ${ }^{7}$ If these signs are present, admission to a specialist centre is recommended. If these signs are not present, nurses then assess weight for age using a growth chart. Children with very low weight (WAZ $<-3$ ) are given nutritional advice and outpatient follow up. Local adaptation of the generic guidelines is encouraged for the implementation of IMCI. ${ }^{8}$
Although the study site (the Royal Victoria Hospital) is a secondary/tertiary referral hospital, the low nurse to patient ratios mean that height measurements for WHZ calculation are not feasible under normal working conditions. In this study, we assessed whether nurses in The Gambia who were trained to use the nutrition algorithm of the IMCI guidelines were able to identify reliably children with severe malnutrition attending outpatient clinics. The study did not assess the detection of anaemia, also included in the nutrition algorithm, or other components of the IMCI guidelines.

\section{METHODS}

Site and participants

All children aged 2-60 months attending the Paediatric Outpatient Clinic of the Royal Victoria Hospital, Banjul during December 2001 and January 2002 were recruited. The hospital is a busy tertiary level facility and children are referred from local and regional health centres.

\section{Nursing staff and $\mathrm{IMCl}$ training}

Four state registered and three auxiliary nurses were trained by $\mathrm{CH}$ and $\mathrm{KK}$ in the IMCI nutrition algorithm. Training materials used were the IMCI training manual, "Assess and classify the sick child age 2 months up to 5 years" and the related IMCI Photograph Manual. ${ }^{5}$ Training materials were given to the nurses for review one week before training. Training was done one-to-one and included a practical component of assessing children with and without severe wasting and/or pedal oedema admitted to hospital. All nurses

Abbreviations: $I M C l$, integrated management of childhood illness; IQR, intraquartile range; PPV, positive predictive value; WAZ score, weight for age $Z$ score; WHZ score, weight for height $Z$ score 
were assessed at the end of the session and showed good knowledge and performance. Nurses undertook the study immediately after completing the training.

\section{Data collection}

Data were recorded on to standard forms. Demographic details were obtained from the Road-to-Health card. A local events calendar was used to determine age when a health card was not available. Signs of protein energy malnutrition, including bipedal oedema, were recorded by KK. The attending physician was consulted to verify any doubtful clinical findings including the presence of oedema. Each child was weighed twice, wearing minimal clothing using an electronic scale (SECA Model 835; Child Growth Foundation, London). In children $<24$ months, length (Rollametre), and in older children, standing height (Traditional Height Measure, CMS Weighing Equipment Limited, UK), was measured three times. Means were used for the final values. The diagnoses and decision regarding admission determined by the attending physician were recorded.

The nurse was blind to these data and was provided only with each child's name, date of birth, and weight. The nurse recorded whether there was visible severe wasting and/or bipedal oedema, and then determined whether each child had a very low weight by calculating the child's age and using the IMCI weight for age chart.

\section{Data analysis}

All data were double entered and WHZ and WAZ scores determined (EPI-INFO, version 6, Centres for Disease Control, Atlanta, USA). WHZ score, WAZ score, and assessment of bipedal oedema by KK were used to evaluate the nurses' assessments.

Ethical approval for the study was granted by the joint Gambia Government/Medical Research Council Ethics Committee.

\section{RESULTS}

A total of 361 children were recruited. Nine children were excluded: five did not fulfil the inclusion criteria, three had incomplete data, and the measurement of one was assumed to be inaccurate on the basis of an extreme value for WHZ score.

Median (intraquartile range; IQR) age was 16.0 (9.8-27.0) months; 208 (59.1\%) were boys. Median (IQR) WHZ score was $-1.34(-2.22$ to -0.55 ; see fig 1$)$. The most common primary diagnoses were malaria $(58.8 \%)$, acute respiratory infections (11.9\%), gastroenteritis $(7.5 \%)$, and skin infection $(4.9 \%)$. No child had a primary diagnosis of malnutrition, but this was a secondary diagnosis in 17 (4.8\%) children.

Thirty four $(9.7 \%)$ children were severely wasted (WHZ score $<-3)$ and $18(5.1 \%)$ children had bipedal oedema.

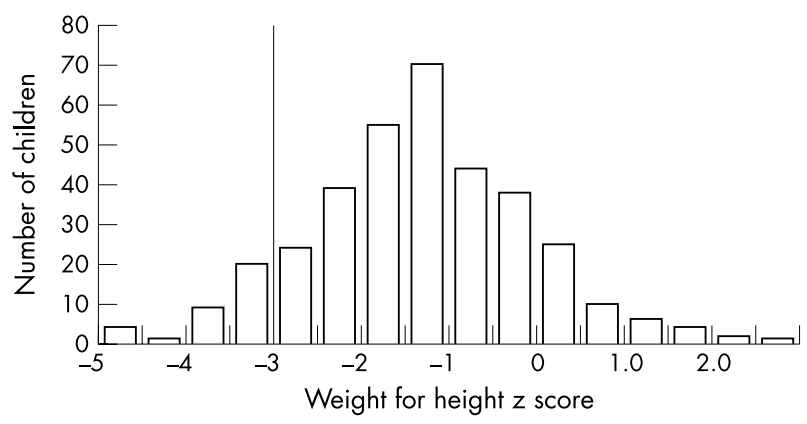

Figure 1 Distribution of weight for height Z score in 352 children. The vertical line is the cut off line for severe malnutrition: WHZ score $<-3$.
Median (IQR) WHZ score for children with bipedal oedema was $-1.74(-2.49$ to -1.06$)$. Only two children had both severe wasting and bipedal oedema. The age distribution, predominance of males, and frequency of primary diagnoses in the malnourished children were similar to the whole group.

The nurses identified visible severe wasting in 34 (9.7\%) children and bipedal oedema in eight $(2.3 \%)$, including three children with both signs. Table l shows the sensitivity, specificity, and positive predictive value of the nurse assessments. Overall, the nurses identified correctly only half of 50 children with severe wasting and/or bipedal oedema. Nurses wrongly identified 15 children as having severe wasting; the median (IQR) WHZ score for these children was $-2.05(-2.61$ to -1.47$)$. Therefore, around half of these children had moderate wasting (WHZ score between $\geqslant 3$ and $<-2)$ and half were better nourished. There were five children with a WHZ score $<-4$, all of whom were picked up by the nurses. The age, sex distribution, and primary diagnoses in the children wrongly diagnosed by the nurses and in those malnourished children missed by the nurses were similar to those correctly identified.

Severe stunting (height for age $\mathrm{Z}$ score $<-3$ ) occurred in 22 children, of whom five were severely malnourished. The nurses appeared to identify children with severe wasting and/ or oedema more reliably in those who also had severe stunting but the confidence interval was wide (sensitivity $71.4 \%$; $95 \%$ CI 38.0 to 104.9 ), but also wrongly identified more cases in this group (specificity 60.0\%; 95\% CI 35.2 to 84.8).

The number of children assessed by each nurse was insufficient to allow assessment of inter-observer differences. However, the performance of the auxiliary nurses was similar to that of the more highly trained staff. The physicians attending the cases correctly recorded a diagnosis of severe malnutrition in 12/50 cases and wrongly identified a further five cases as severely malnourished.

Table 2 shows the additional clinical signs of malnutrition recorded by KK according to nutritional status. All signs were detected more frequently in severely malnourished than nonmalnourished children. However, each occurred only in the minority of severe cases.

\section{DISCUSSION}

Severe protein-energy malnutrition was common in children attending this clinic, occurring in more than one in ten children. Using the IMCI nutrition algorithm, the nurses did not identify malnourished children reliably; sensitivity and PPV were uniformly low for all outcomes. The net result was many severely malnourished children were not detected and therefore did not receive appropriate treatment regimes. Although specificities appeared to be good, this still resulted in many non-severely malnourished children being wrongly identified, and, among these, half had moderate malnutrition with the remainder being better nourished. Scarce resources may therefore be targeted at less needy children.

Could this poor performance have resulted from inadequate training? The training focused on the nutritional algorithm only (excluding anaemia), used IMCI materials, and included practical experience and assessment. The study was undertaken immediately on completion of the training exercise. Therefore, we consider that the training delivered was adequate. Also, it is unlikely that better training in the nutritional algorithm will occur in practice when training in the complete IMCI guidelines is delivered. The 100\% accuracy in detecting children with more severe malnutrition (WHZ score $<-4$ ) suggests that the nurses were correctly identifying the signs but only when they were more apparent. Our findings are similar to a previous small study where, 
Table 1 Nurses' performance using IMCl guidelines in identifying children with severe protein-energy malnutrition

\begin{tabular}{|c|c|c|c|c|}
\hline \multirow[b]{2}{*}{ Indices of severe malnutrition } & \multirow[b]{2}{*}{$\begin{array}{l}\text { "True" number (\%) of } \\
\text { cases" }\end{array}$} & \multicolumn{3}{|c|}{ Nurses' assessments } \\
\hline & & $\begin{array}{l}\text { Sensitivity } \\
\text { n }(\%) \\
{[95 \% \mathrm{Cl}]}\end{array}$ & $\begin{array}{l}\text { Specificity } \\
\text { n (\%) } \\
{[95 \% \mathrm{Cl}]}\end{array}$ & $\begin{array}{l}\text { PPV } \\
\text { n (\%) } \\
{[95 \% \mathrm{Cl}]}\end{array}$ \\
\hline Severe wasting & $34 / 352(9.7)$ & $\begin{array}{l}\text { 19/34 (55.9) } \\
{[39.2 \text { to } 72.6]}\end{array}$ & $\begin{array}{l}303 / 318(95.3) \\
{[93.0 \text { to } 97.6]}\end{array}$ & $\begin{array}{l}19 / 34(55.9) \\
{[39.2 \text { to } 72.6]}\end{array}$ \\
\hline Bipedal oedema & $18 / 352(5.1)$ & $\begin{array}{l}4 / 18(22.2) \\
{[3.0 \text { to } 41.4]}\end{array}$ & $\begin{array}{l}331 / 334(99.1) \\
{[98.1 \text { to } 100.1]}\end{array}$ & $\begin{array}{l}4 / 7(57.1) \\
{[20.4 \text { to } 93.8]}\end{array}$ \\
\hline Severe wasting and/or bipedal oedema & $50 / 352(14.2)$ & $\begin{array}{l}25 / 50(50.0) \\
{[36.1 \text { to } 63.9]}\end{array}$ & $\begin{array}{l}289 / 302(95.7) \\
{[93.4 \text { to } 98.0]}\end{array}$ & $\begin{array}{l}25 / 38(65.8) \\
{[50.7 \text { to } 80.9]}\end{array}$ \\
\hline Very low weight for age & $50 / 352(14.2)$ & $\begin{array}{l}31 / 50(62.0) \\
{[48.5 \text { to } 75.5]}\end{array}$ & $\begin{array}{l}297 / 301(98.7) \\
{[97.4 \text { to } 100.0]}\end{array}$ & $\begin{array}{l}31 / 35(88.6) \\
{[78.1 \text { to } 99.1]}\end{array}$ \\
\hline
\end{tabular}

*Nurses' assessments were compared with number of children with severe wasting defined as WHZ score $<-3$; bipedal oedema identified by a trained observer and very low weight for age defined as WAZ score $<-3$.

compared with a paediatrician, health workers correctly identified four out of six children as severely wasted. ${ }^{9}$ Ongoing training and supervision, and identifying and addressing the health workers' individual difficulties, particularly with the more subtle changes, may improve the performance.

Were the methods used to assess the nurses' performance appropriate? A weight for height $\mathrm{Z}$ score $<-3$ has often been used to identify severely wasted children, ${ }^{10}$ and in this study, was derived accurately from measurements of weight and height. The "gold standard" for bipedal oedema was more difficult, and the nurses' sensitivity in detecting this sign was worse than for the other indices. We used one trained observer (KK) who sought assistance from the attending physician if needed. However, the physicians themselves performed poorly in recognising severely malnourished children. Therefore, although it would be difficult to devise a better gold standard for use in a working environment, our findings regarding the detection of bipedal oedema are less secure than for the other indices. Despite completing training recently, direct observation suggested that nurses spent insufficient time depressing the tissues when detecting oedema. More emphasis on this during training may be useful.

Were there other contributing factors? The study took place at a time of year when food availability was improving. Nurses may have had a higher threshold for identifying severe protein-energy malnutrition, expecting that children's nutritional status would improve, than at other times of the year. Repeating the study at a time of year when food was less available would address this issue.

As may be expected, there was a suggestion that nurses identified severe, acute malnutrition more easily in children who also had chronic malnutrition (severe stunting) but, on the other hand, over-diagnosed acute malnutrition in stunted

Table 2 Clinical signs according to nutritional status

\begin{tabular}{lcl}
\hline $\begin{array}{l}\text { Clinical sign of } \\
\text { malnutrition }\end{array}$ & $\begin{array}{l}\text { Severely } \\
\text { malnourished* } \\
(\mathbf{n}=50)\end{array}$ & $\begin{array}{l}\text { Not severely } \\
\text { malnourishedt } \\
(\mathbf{n}=302)\end{array}$ \\
\hline $\begin{array}{l}\text { Angular chelitis } \\
\text { Sparse fragile hair }\end{array}$ & $10(20 \%)$ & $22(7.3 \%)$ \\
Hair depigmentation & $1(2 \%)$ & $10(3.3 \%)$ \\
Oral thrush & $3(6 \%)$ & $3(1 \%)$ \\
Skin changes & $4(8 \%)$ & $9(2.9 \%)$ \\
Anaemia & $14(28 \%)$ & $3(1 \%)$ \\
Altered affect & $4(8 \%)$ & $43(14.2 \%)$ \\
\hline
\end{tabular}

*WHZ score $<-3$ and/or bipedal oedema.

$+\mathrm{WHZ}$ score $\geqslant-3$ and no bipedal oedema. children. However, the number of severely stunted children was small and differences in nurses' performance were not statistically significant.

The children in this study were assessed at a tertiary referral centre. Are our findings relevant to the detection of severe malnutrition in children attending primary level health facilities? It is likely that performance in primary level clinics would be worse than in the hospital setting. Although, in The Gambia, the grades of nurses working in the hospital clinic are similar to those working in primary level clinics, the hospital based nurses see many more children with malnutrition and, therefore, would be expected to be more skilled in their recognition. Also, even at the same level of specificity, the number of wrongly diagnosed malnutrition cases ("false positives") would be expected to increase at the primary level where the frequency of malnutrition is lower.

Our findings of low accuracy in plotting weight for age differed from a previous study in Ethiopia that looked at the performance of six health workers trained in IMCI management, ${ }^{9}$ where only two patients out of 449 were misclassified. This study was undertaken in a more controlled research environment, with one field worker appointed to assess only seven children per day. In our study there were nine health workers involved, assessing much larger numbers of children and continuing their normal workload. Direct observation in our study showed that nurses found accurate calculation of age from dates of birth difficult. This step is not included in the IMCI training materials where ages of children are given, and explains why nurses performed well in the assessments after training but poorly in practice. The training materials should be modified to include calculation of age.

Our findings suggest that modifications to the current IMCI nutrition algorithm should be considered. Although we did not test the ability of nurses to identify other clinical signs of malnutrition (angular cheilitis, skin changes, etc ${ }^{11}$ ), the low frequency of these signs in children with severe malnutrition in this study suggests that they would not be useful additions to the algorithm. Although low, mid, and upper arm circumference in $1-5$ year olds has been shown to identify a slightly different population from low WHZ score, ${ }^{12}$ it appears to be a predictor of childhood mortality in community studies. ${ }^{13}$ This measurement does not require calculation of exact age and should be explored.

Finally, it should be noted that this study focused only on severe wasting and bipedal oedema, and the identification of severe anaemia and other symptoms and signs that would prompt referral and/or admission were not tested. Therefore, it is possible that some of the children in whom severe malnutrition was missed may have been selected for referral 
or admission based on other IMCI criteria (for example, severe anaemia, inability to feed).

\section{Conclusions}

Nurses trained to use the IMCI nutrition algorithm only identified about half of severely malnourished Gambian children attending clinics, and also frequently wrongly diagnosed malnutrition. Accuracy did, however, improve with greater degrees of malnutrition. Identifying children with very low weight using a weight for age chart was also unreliable. Both moderate and severe malnutrition are highly prevalent and significant causes of avoidable morbidity and mortality in developing countries. Finding more reliable ways to help health workers to identify malnourished children, with improved training materials and better ongoing supervision are high priorities.

\section{ACKNOWLEDGEMENTS}

The authors would like to thank the nurses and children involved, Momodou Sanneh and Mohammed Alhajie for practical help, and the Chief Executive, Dr Pamela Esangbedo, and the management of the Royal Victoria Hospital, Banjul, The Gambia. We would also like to acknowledge Dr Martin Weber's encouragement to undertake this study.

\section{Authors' affiliations}

C Hamer, Royal Victoria Hospital, Banjul, The Gambia

K Kvatum, University of Minnesota, USA

D Jeffries, S Allen, Fajara, Banjul, The Gambia

\section{REFERENCES}

1 World Health Organisation Statistical Information System, 1999. htp:// www.who.int/nut/documents/nhd_mip_2000.pdf.

2 Pelletier DL. The effects of malnutrition on child mortality in developing countries. Bull World Health Organ 1995;73:443-8.

3 Man WD-C, Weber M, Palmer A, et al. Nutritional status of children admitted to hospital with different diseases and its relationship to outcome in the Gambia, W. Africa. Trop Med Int Health 1998;3:678-86.

4 Schofield C, Ashworth A. Why have mortality rates for severely malnourished children remained so high? Bull World Health Organ 1996;74:223-9.

5 World Health Organisation, Division of Diarrhoeal and Acute Respiratory Disease Control, and UNICEF. WHO severe malnutrition manual. Management of childhood illness: assess and classify the sick child age 2 months up to 5 years. United Republic of Tanzania, 1998:93-105.

6 Gove S, for the WHO working Group. Integrated management of childhood illness by out-patient health workers: technical basis and overview. Bull World Health Organ 1997;75(suppl 1):7-24.

7 Bern C, Zucker JR, Perkins BA, et al. Assessment of potential indicators for protein-energy malnutrition in the algorithm for integrated management of childhood illness. Bull World Health Organ 1997;75(suppl 1):87-96.

8 WHO Division of Child Health and Development. Integrated management of childhood illness (IMCI): conclusions. Bull World Health Organ 1997;75(suppl 1):119-28.

9 Simoes EAF, Desta T, Tessema T, et al. Performance of health workers after training in integrated management of childhood illness in Gondar, Ethiopia. Bull World Health Organ 1997;75(suppl 1):43-53.

10 WHO Working Group. Use and interpretation of anthropometric indicators of nutritional status. Bull World Health Organ 1986;64:929-41.

11 Hillman RW. Concordance among clinical signs suggestive of malnutrition. Am J Clin Nutr 1967;20(10):118-24.

12 Gayle HD, Binkin NJ, Stachling NW, et al. Arm circumference v. weight for height in nutritional assessment: Are the findings comparable? J Trop Paediatr 1988;34:213-17.

13 Chen LC, Chowdhury A, Huffman SL. Anthropometric assessment of energyprotein malnutrition and subsequent risk of mortality among pre-school aged children. Am J Clin Nutr 1980;33:1836-45. 